\title{
Development of an Entrepreneurial Mind-set within a Three-Semester Me- chanical Engineering Capstone Design Sequence Based on the SAE Collegiate Design Series
}

\section{Dr. James A. Mynderse, Lawrence Technological University}

James A. Mynderse, PhD is an Associate Professor in the A. Leon Linton Department of Mechanical Engineering at Lawrence Technological University. His research interests include mechatronics, dynamic systems, and control with applications to piezoelectric actuators, hysteresis, and perception. He serves as the faculty advisor for the LTU Baja SAE team.

Dr. Liping Liu, Lawrence Technological University

Liping Liu is an Associate Professor in the A. Leon Linton Department of Mechanical Engineering at Lawrence Technological University. She earned her Ph.D. degree in Mechanical Engineering from University of Illinois at Urbana-Champaign in 2011. Her research focuses on thermal sciences and energy systems, with special interest in addressing transport phenomena in energy processes. She is a member of ASEE, ASME, and SAE International.

\section{Dr. Andrew L. Gerhart, Lawrence Technological University}

Andrew Gerhart, Ph.D. is an Associate Professor of Mechanical Engineering at Lawrence Technological University. He is actively involved in ASEE, the American Society of Mechanical Engineers, and the Engineering Society of Detroit. He serves as Faculty Advisor for the American Institute of Aeronautics and Astronautics Student Chapter at LTU, chair of the First Year Engineering Experience committee, chair for the LTU KEEN Course Modification Team, chair for the LTU Leadership Curriculum Committee, supervisor of the LTU Thermo-Fluids Laboratory, coordinator of the Certificate/Minor in Aeronautical Engineering, and faculty advisor of the LTU SAE Aero Design Team. Dr. Gerhart conducts workshops on active, collaborative, and problem-based learning, entrepreneurial mindset education, creative problem solving, and innovation. He is an author of a fluid mechanics textbook.

\section{Dr. Robert W. Fletcher, Lawrence Technological University}

Robert Fletcher joined the faculty of the Mechanical Engineering Department at Lawrence Technological University in the summer of 2003, after two decades of various industry engineering positions in research, and product development.

Dr. Fletcher earned his Bachelor of Science Degree in Chemical Engineering from the University of Washington, in Seattle, and the Master of Science and Ph.D. degrees in Chemical Engineering, both from the University of Michigan.

He teaches a number of alternative energy courses at Lawrence Tech. Dr. Fletcher and his student research team is focusing on energy usage and efficiencies of several traditional and alternative energy systems.

\section{Dr. Hamid Vejdani, Lawrence Technological University}

Hamid Vejdani, $\mathrm{PhD}$ is an Assistant Professor in the A. Leon Linton Department of Mechanical Engineering at Lawrence Technological University. His research interests include dynamical modeling, control and robotics.

\section{Dr. Wuming Jing, Lawrence Technological University}

Wuming Jing received his B.S. and M.S. from Harbin Institute of Technology, China and Xi' an Jiaotong University, China, in 2006 and 2009, respectively, both in Mechanical Engineering. He earned his Ph.D. from Stevens Institute of Technology in 2013, also majored in Mechanical Engineering, focusing on microrobotics. He continued microrobotic research at Purdue University as postdoctoral associate before joining LTU at 2016. At LTU, he teaches mechanical and robotic courses. His research interest is on the novel robotics on micro-scales, especially meeting the engineering challenges. 


\section{Dr. Kingman E. Yee, Lawrence Technological University}

Kingman Yee is an associate professor of mechanical engineering and the program director for the Master of Science in Automotive Engineering. In addition, he is faculty co-advisor for the Collegiate Chapter of SAE and the Blue Devil Motorsports Organization. 


\title{
Development of an Entrepreneurial Mindset within a Three- Semester Mechanical Engineering Capstone Design Sequence Based on the SAE Collegiate Design Series
}

\begin{abstract}
Mechanical engineering seniors at Lawrence Technological University (LTU) complete a capstone design project: either an SAE collegiate design series (CDS) competition or an industry-sponsored project (ISP). Starting in 2015, the LTU CDS advisors worked together to redesign the five-credit three-semester sequence. The overall goals of the modifications were to improve student design, project management and communication skills; integrate SAE CDS projects into the actual class time; and increase faculty advisor involvement in the classroom. In parallel with senior design modifications, faculty recently completed a multiyear process to incorporate active and collaborative learning (ACL), problem-based learning (PBL), and entrepreneurially minded learning (EML) into the engineering curriculum. Leveraging the curriculum-wide course modifications, the CDS advisors also incorporated ACL and EML components into the capstone design changes.

Student demonstration of example behaviors associated with an entrepreneurial mindset were assessed using student surveys in the Introduction to Projects course (the beginning of the sequence) and Competition Projects 2 course (the end of the sequence) at the conclusion of the Spring 2018 semester. The results indicate that the capstone projects are great venues for students to work collaboratively and practice entrepreneurial skills. For example, students have to "integrate information from many sources to gain insight" and need to "persist through failure" throughout this 18 month long project. Most of the students admit that they need to almost always work as a team, and also to "understand the motivations and perspectives of others." They also agree that through the capstone design project they have improved skills in project organization, time management, and project management. The survey results will be used to guide additional development of classroom materials to better foster the entrepreneurial mindset.
\end{abstract}

\section{Introduction}

Capstone projects provide engineering students the opportunity to solve real-world, open-ended engineering projects, and have been highly regarded as important learning activities. Within mechanical engineering, these capstone projects serve as a summative assessment, bringing together machine design, thermo-fluids, manufacturing, and mechatronics topics into a realworld design experience. Relative coverage of these topics depends strongly on the particular design project in which each student is involved. Mechanical engineering seniors at Lawrence Technological University (LTU) complete a capstone design project: either an industrysponsored project (ISP) or an SAE collegiate design series (CDS) vehicle. 
ISPs represent time-sensitive real-world problems brought to the department by industry partners. Students may be involved with a single project or parts of two different projects. For a larger project, one semester may include research into the problem, design of a solution, validation of the design using appropriate software tools or calculations, and a report to the industry partner detailing the proposed design. Another semester may include fabrication of a working prototype, validation of the prototype, and a presentation of the final design and prototype to the industry sponsor. Each student is assessed using monthly progress reports and the team is assessed using a comprehensive report each semester, poster, and oral presentations. Examples of past ISPs include a fluid-powered gantry crane [1] and a decoupler for driveline dynamics [2].

For the SAE CDS competition track, LTU students compete in Baja SAE, Formula SAE, Formula Electric division of Formula Hybrid, SAE Aero Design, and SAE Supermileage. Collectively, these LTU teams are referred to as Blue Devil Motorsports (BDM). Each student team designs, builds, and competes with their vehicle at one or more of the SAE CDS events. While some details of the SAE rules may change for each competition year, the overall objectives and outcomes of these competitions remain similar from year to year. Previous student team vehicles are available for students to reference, transforming the project from an entirely new design into a process of continual improvement. Timelines are based on SAE deliverables and competition dates, which prevents extensions or spillover from semester to semester.

Starting in 2015, the LTU CDS faculty advisors worked together to redesign the five-credit three-semester capstone design sequence [3]. LTU semesters are 16 weeks long. The overall goals of the modifications were to improve student design, project management and communication skills; integrate SAE CDS projects into the actual class time; and increase faculty advisor involvement in the classroom. Each of the three courses in the new sequence was redesigned with learning outcomes aligned with Bloom's taxonomy [4] and session-by-session schedules to support the learning outcomes. Direct and indirect assessment supports the conclusion that students are improving in relevant technical skills and that the course modifications are improving performance [5]. The present article assesses the impact of the three-semester sequence on development of an entrepreneurial mindset in the CDS capstone design experience.

\section{Three Semester Course Sequence}

A brief description of the three course sequence is provided below. Details on the learning objectives, session-by-session class schedule, and assessment of technical dimensions of the learning objectives were previously described in [5] and are not repeated here except as necessary to describe those features associated with an entrepreneurial mindset.

The capstone design sequence for CDS students consists of three courses: Introduction to Projects, Competition Projects 1, and Competition Projects 2, as shown on the BSME flowchart in Figure 1. Introduction to Projects runs during the Spring semester and introduces students to the CDS projects while using a small-scale "designette" $[6,7]$ to practice the engineering design process and project management. Competition Projects 1 follows in the Fall semester and delivers technical content with studio-like design sessions. Competition Projects 2 completes the 
sequence in the following Spring semester and includes show-and-tell sessions and design presentations from each team. In April, LTU hosts the annual Blue Devil Motorsports Unveiling event, where all vehicles are presented to the University and sponsors prior to competition travel. The credits and offerings for the courses are tabulated in Table 1.

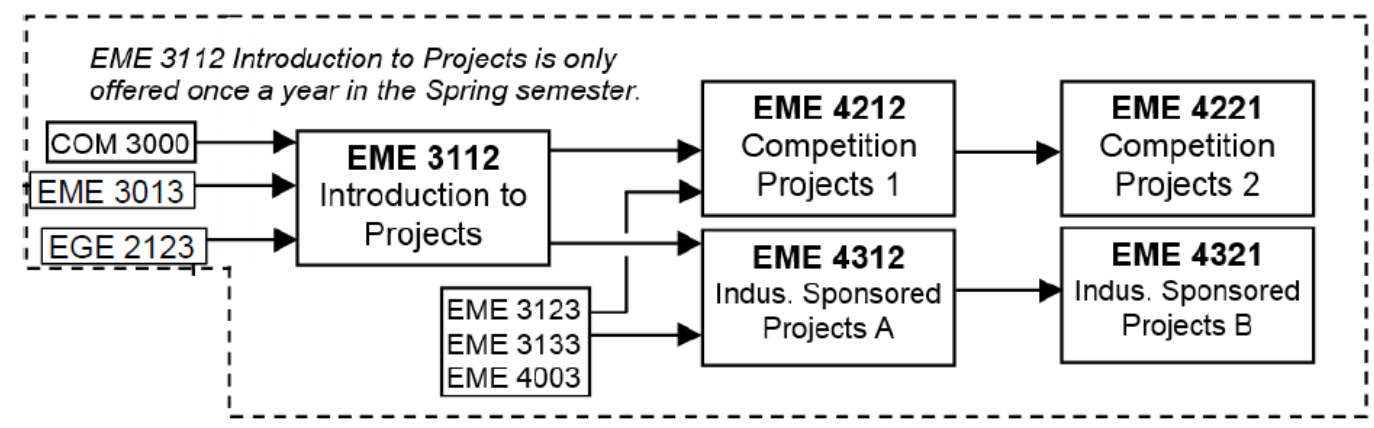

Figure 1. Capstone design portion of BSME flowchart.

Table 1. Course offering schedule.

\begin{tabular}{|l|c|c|c|}
\hline & Credits & Spring & Fall \\
\hline Introduction to Projects & 2 & $\mathrm{X}$ & \\
\hline Competition Projects 1 & 2 & & $\mathrm{X}$ \\
\hline Competition Projects 2 & 1 & $\mathrm{X}$ & \\
\hline
\end{tabular}

Each CDS team has a faculty advisor and the three-semester sequence has a course coordinator, as shown in Table 2. Years of CDS experience are also provided for each advisor. Each CDS team is provided with a lab space within the Applied Research Center (ARC) building. The ARC also includes a machine shop, an independent four wheel chassis dynamometer, a small chassis dynamometer, two water-brake engine dynamometers (to accommodate different engine sizes), and a wind tunnel. A project engineer oversees the ARC and maintains equipment.

Table 2. SAE competition team advisor and course coordinator.

\begin{tabular}{|l|c|c|}
\hline Team & Advisor & $\begin{array}{c}\text { Advisor Years } \\
\text { of Experience }\end{array}$ \\
\hline Baja SAE & $\mathrm{M}$ & 6 \\
\hline Formula SAE & $\mathrm{J}$ & 2 \\
\hline $\begin{array}{l}\text { Formula Electric } \\
\text { (previously Formula Hybrid) }\end{array}$ & $\mathrm{V}$ & 0 \\
\hline SAE Aero Design & $\mathrm{G}$ & 15 \\
\hline SAE Supermileage & $\mathrm{L}$ & 4 \\
\hline Course Coordinator & $\mathrm{Y}$ & 8 \\
\hline
\end{tabular}

\section{Entrepreneurially Minded Learning}

In parallel with capstone design modifications, LTU faculty completed a multiyear process to incorporate active and collaborative learning (ACL), problem-based learning (PBL), and entrepreneurially minded learning (EML) into the engineering curriculum [8]. Approximately $75 \%$ of the engineering curriculum, including mathematics and general education courses, has 
been modified to include ACL and PBL with entrepreneurial mindset attributes. These courses span the curriculum from multidisciplinary Introduction to Engineering $[9,10]$ to undergraduate courses $[11,12]$ to graduate level mechatronic design [13].

Each competition within the CDS requires active participation and student collaboration, making these good examples of ACL [14, 15]. By providing student teams with scaffolding and a mix of in-class and out-of-class activities, these capstone design projects are a subset of ACL called PBL [16]. The literature supports the use of PBL to develop technical engineering skills as well as professional skills. PBL activities can substantially improve long-term student learning [17, $18,19]$ and skill development [19]. Cooperative learning promotes academic success, quality of relationships, and self-esteem [20].

A new approach to PBL activities is the inclusion of student skills associated with an entrepreneurial mindset, such as integrating information from many sources to gain insight, conveying engineering solutions in economic terms, and identifying unexpected opportunities. The resulting EML activities emphasize "discovery, opportunity identification, and value creation with attention given to effectual thinking over causal (predictive) thinking" [21].

As a member school in the Kern Entrepreneurial Engineering Network (KEEN), LTU uses the KEEN framework [22] to define an entrepreneurial mindset. The KEEN framework begins with the "three Cs" of Curiosity, Connections, and Creating Value [23]. Each element is supported by example student behaviors that describe typical actions displayed by those operating with an entrepreneurial perspective. For instance, Curiosity is demonstrated by "explore a contrarian view of accepted solutions" and Creating Value is demonstrated by "identify unexpected opportunities to create extraordinary value." The framework continues from the three Cs to Engineering Thought and Action, Collaboration, Communication, and Character. As with the three Cs, each concept is supported by example student behaviors. In total, the framework includes 18 example student behaviors, as shown in Figure 2.

The entrepreneurial mindset, as defined by the KEEN framework and LTU, is not the same as entrepreneurship. The entrepreneurial mindset is the application of the "three Cs" to engineering practice and not necessarily the creation of new business. Inclusion of entrepreneurial education is a valuable addition to the traditional engineering curriculum $[24,25,26]$ and aligns with portions of ABET Criterion 3 a-k [27], though more discussion is warranted with approved ABET student outcome revisions [28]. 


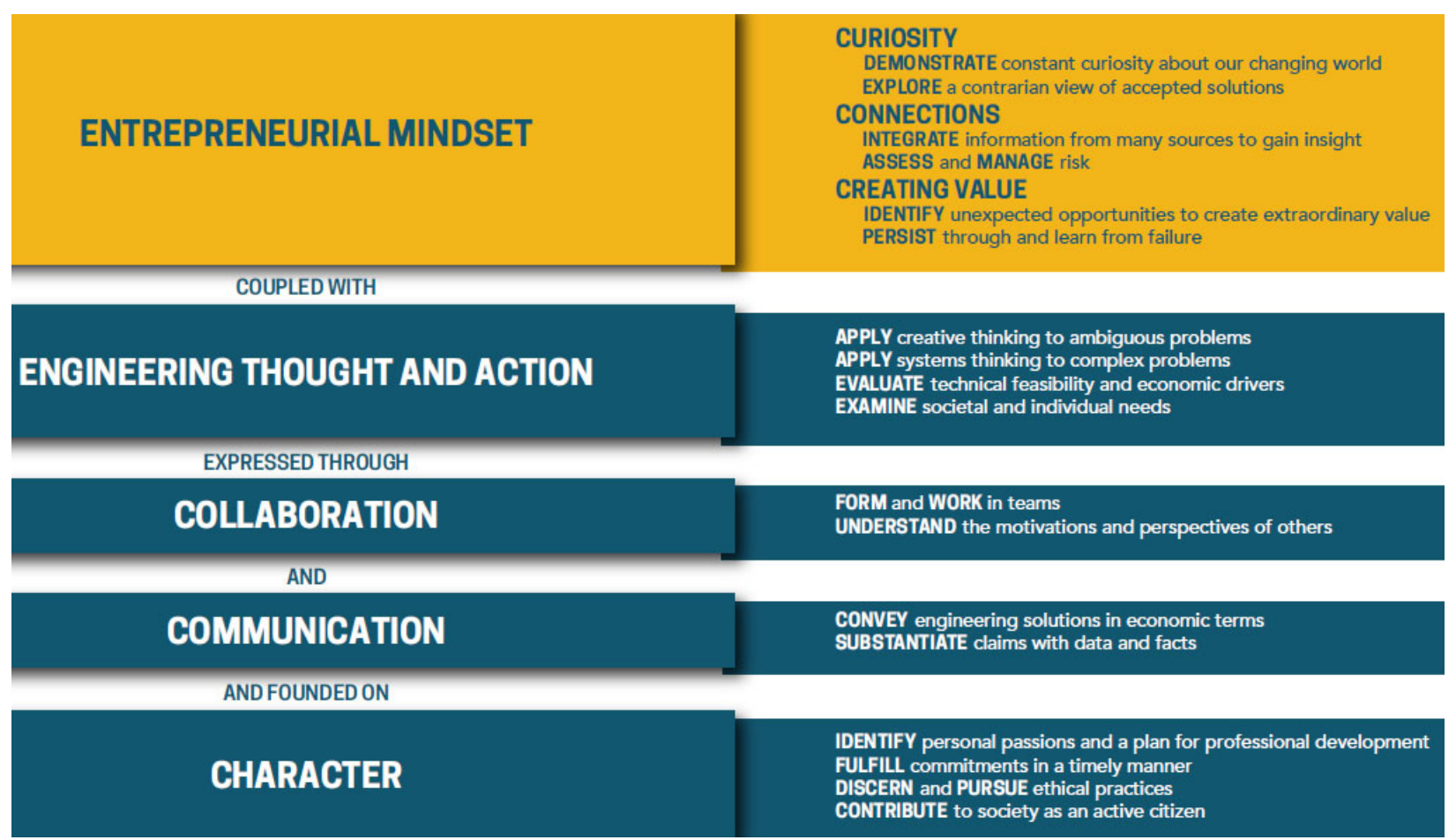

Figure 2. Entrepreneurial mindset learning objectives and example behaviors as presented in the KEEN framework [22].

As described above, learning objectives for the three-semester sequence are provided in [5]. Each learning objective was assigned to a Bloom's taxonomy level [4] making it possible to ensure that objectives are appropriate to the course level. Bloom's taxonomy levels are given by:

(1) Knowledge

(2) Comprehension

(3) Application

(4) Analysis

(5) Synthesis

(6) Evaluation

The subset of learning objectives for Introduction to Projects (Spring) associated with an entrepreneurial mindset are as follows with Bloom's taxonomy levels in parentheses. Each learning objective is also matched to associated entrepreneurial mindset example behaviors as defined in the KEEN framework.

- (1) Match personal skillset and mindset to available capstone design teams. [IDENTIFY personal passions]

- (2) Describe the importance of a team. [FORM and WORK in teams]

- (2) Distinguish between a contributing and a poor team member.

[WORK in teams, UNDERSTAND the motivations and perspectives of others]

- (5) Organize team for selected capstone design project.

[WORK in teams] 
- (3) Predict time allocation for major designette milestones.

[ASSESS and MANAGE risk, FULFILL commitments in a timely manner]

- (3) Practice defining the correct problem.

[APPLY creative thinking to ambiguous problems, APPLY systems thinking to complex problems]

- (3) Demonstrate multiple brainstorming techniques.

[DEMONSTRATE constant curiosity about our changing world, EXPLORE a contrarian point of view, IDENTIFY unexpected opportunities to create extraordinary value]

- (2) Distinguish between multiple solutions on the basis of viability.

[INTEGRATE information from many sources to gain insight]

- (3) Demonstrate best practices for oral and graphical communication.

[CONVEY engineering solutions in economic terms, SUBSTANTIATE claims with data and facts]

- (2) Discuss budget and funding for assigned capstone design project.

[IDENTIFY unexpected opportunities to create extraordinary value]

The subset of learning objectives for Competition Projects 1 (Fall) associated with an entrepreneurial mindset are as follows with Bloom's taxonomy levels in parentheses. Each learning objective is also matched to associated entrepreneurial mindset example behaviors as defined in the KEEN framework.

- (5) Develop an organizational chart and timeline for the design project. [WORK in teams]

- (3) Interact with stakeholders including customers, suppliers, subject matter experts, management, and university support.

[UNDERSTAND the motivations and perspectives of others]

- (5) Persist through individual, group, or team failure

[PERSIST through and learn from failure]

- (5) Propose the value of the design in economic terms.

[EVALUATE technical feasibility and economic drivers]

- (2) Communicate the value of the design in economic and engineering terms.

[CONVEY engineering solutions in economic terms, SUBSTANTIATE claims with data and facts]

- (3) Practice time management skills through the design project.

[ASSESS and MANAGE risk, FULFILL commitments in a timely manner]

- (5) Manage project cost and funding at all stages of development.

[IDENTIFY unexpected opportunities to create extraordinary value, EVALUATE technical feasibility and economic drivers]

- (3) Develop a fundraising strategy and action plan according to the target budget.

[IDENTIFY unexpected opportunities to create extraordinary value]

- (3/4) Illustrate the impact of the triple bottom line on the design project.

[EXAMINE societal and individual needs, DISCERN and PURSUE ethical practices] 
The subset of learning objectives for Competition Projects 2 (Spring) associated with an entrepreneurial mindset are as follows with Bloom's taxonomy levels in parentheses. Each learning objective is also matched to associated entrepreneurial mindset example behaviors as defined in the KEEN framework.

- (6) Justify through presentation the value of the vehicle.

[EVALUATE technical feasibility and economic drivers, CONVEY engineering solutions in economic terms, SUBSTANTIATE claims with data and facts]

Entrepreneurial mindset learning objectives in Introduction to Projects (Spring) were supported by class sessions on the importance of a team, project time management, creative problem solving, and communication skills. Entrepreneurial mindset learning objectives in Competition Projects 1 (Fall) were supported by class sessions on value proposition and formal design presentations with advisor feedback. Entrepreneurial mindset learning objectives in Competition Projects 2 (Spring) were supported by formal design presentations and sales pitches with advisor feedback. Many of the entrepreneurial mindset learning objectives in Competition Projects 1 and 2 were also addressed individually by advisors during regular team meetings.

\section{Survey of Entrepreneurial Mindset Indicators}

At the conclusion of the Spring 2018 semester, students in Introduction to Projects and Competition Projects 2 were asked to complete a survey on their projects, their personal demonstration of example behaviors associated with an entrepreneurial mindset, and improvements in their individual organizational and technical skills. Because mindset is based on behaviors and methods of thinking, indirect assessment via surveys is at present the preferred method of assessment. Admittedly, measuring shifts in mindset is not a simple task, especially when measuring the impact due to a course revision. It would be impractical (and potentially unethical) to administer the course using the original format (especially when the faculty noted that the original format was indicating poor performance from the students). Therefore there is no control data to compare with the survey results from the revised courses. Additionally, preand post-course assessments for each of the three capstone courses is not a goal of the present study. Instead the authors are interested in measuring the mindset at the conclusion of the first of the three courses and at the conclusion of the last of the three courses. Methods and results of the survey relating to the entrepreneurial mindset are presented below.

Administration of the survey at the completion of the Spring semester corresponds to completion of the designette in Introduction to Projects and either completion or near completion of the CDS project in Competition Projects 2 (since different CDS teams have different competition dates). Surveys were administered using Google Forms with links distributed to enrolled students. Use of Google Forms, instead of a mandatory paper survey, no doubt contributed to a low response rate. While each CDS team includes both students engaged in the three-semester capstone design sequence (i.e., juniors and seniors) and volunteer underclassmen (i.e., freshmen and sophomores), no effort was made to survey underclassmen. This will be addressed in future work. 
The survey included a note to students at the beginning: "The following survey is used purely for assessment. The goal of this survey is to assess the project activities. It will remain confidential and will not contribute to your grade. Please answer the statements below as honestly and fairly as you can. There are no right or wrong answers, only honest ones." Email addresses were collected only for the purpose of eliminating duplicate responses.

The first portion of the survey included demographic information: student gender, class (junior or senior), and enrolled course (Introduction to Projects or Competition Projects 2). Of the 37 total responses, there was 1 female student. Next, students were asked to respond to several general prompts with a 5-point Likert scale: "I consider the results of my project successful," "I found my work on the project to be satisfying," "The real-world application of the project motivated me to do my best work," and "The open-ended nature of the project motivated me to do my best work." Details on survey results associated with general prompts are provided in [5].

The third section of the survey focused on example behaviors associated with an entrepreneurial mindset. Students were asked to what extent did they demonstrate specific example behaviors with a 5-point scale ranging from "none at all" to "throughout most of the project," as shown in Figure 3. The example behaviors surveyed correspond to 13 of the 18 example behaviors from the KEEN framework [22]. A $14^{\text {th }}$ example behavior was evaluated by asking students to what extent did they work with their team with a 5-point scale ranging from "almost never" to "almost always," as shown in Figure 3. Finally, students were asked to respond to prompts about skill improvements in project organization, time management, and project management with a 5-point Likert scale, as shown in Figure 4. These were not dimensions of the entrepreneurial mindset as defined by the KEEN framework, but are valuable components of a capstone project that extend beyond the design and validation of a CDS vehicle. Details on survey results associated with an entrepreneurial mindset are provided below.

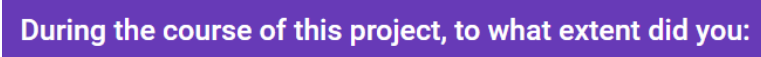

$\begin{array}{ll}\bigcirc \text { none at all } & \bigcirc \text { almost never } \\ \text { slightly } & \bigcirc \text { rarely } \\ \text { on some occasions } & \bigcirc \text { sometimes } \\ \text { many times } & \bigcirc \text { often } \\ \text { throughout most of the project } & \bigcirc \text { almost always }\end{array}$

Figure 3. Example survey questions related to dimensions of the entrepreneurial mindset. 


\section{This project improved my technical skills in:}

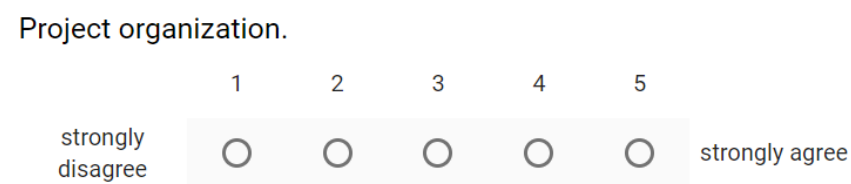

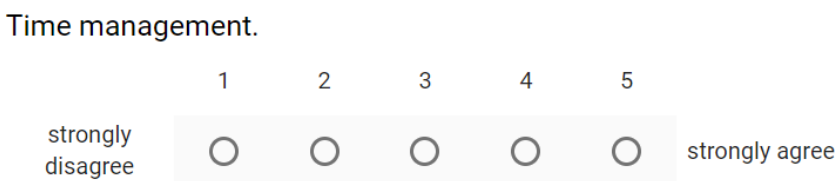

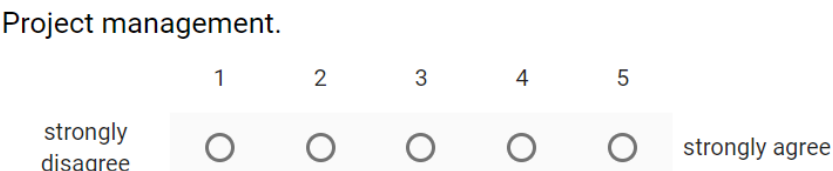

Figure 4. Survey questions related to project management skills.

The fourth portion of the survey asked students to respond to prompts about improvement in technical skills with a 5-point Likert scale. Details on survey results associated with technical skills are provided in [5]. Finally, students were provided with several open-ended response prompts: "What did you like (or appreciate) about the project?", "What should be changed?", and "Additional comments/observations."

\section{Results and Discussion}

As a small University, sample sizes were low. In particular, the response rate for Engineering Projects 2 was especially low. This may be due to the decision to administer the survey at the end of the last semester for many graduating seniors. Samples sizes were $\mathrm{N}=27$ for Introduction to Projects and $\mathrm{N}=10$ for Competition Projects 2 . With low sample sizes, only mean responses and histograms of responses are presented. Future work will include efforts to increase response rates to facilitate additional analysis.

Table 3 presents students' average ratings of their demonstration of example behaviors associated with an entrepreneurial mindset. Average responses for most example behaviors were varied, ranging from "slightly" to "many times." The highest average rating ("many times") was associated with "persist through failure" (mean 3.81 and 4.00). This is not surprising due to the many opportunities to experience setbacks over the duration of the capstone design projects. The next highest ratings were in response to "integrate information from many sources to gain insight" (mean 3.63 and 3.80), "substantiate claims with data and facts" (mean 3.67 and 3.60), and "apply creating thinking to ambiguous problems" (mean 3.56 and 3.60). These example behaviors are clearly associated with open-ended design projects.

The least demonstrated example behaviors were "evaluate economic drivers" (mean 3.19 and 2.40), "create extraordinary value for a customer or stakeholder" (mean 3.22 and 2.40), and "identify an unexpected opportunity for your design" (mean 3.07 and 2.90). The discrepancies in 
mean ratings between the two courses also indicate a difference in the projects between the "designette" in Introduction to Projects that has a clear customer (advisor and current seniors) and the full CDS vehicles with a fictitious customer. Differences in the emphasis on business plan development among the CDS competitions likely also affect these results.

Table 3. Students' average ratings of demonstration of example behaviors associated with an entrepreneurial mindset. Using scale of 1 to 5, 1 indicates "none at all" and 5 indicates "throughout most of the project."

\begin{tabular}{|l|c|c|}
\hline & $\begin{array}{c}\text { Introduction } \\
\text { to Projects } \\
\text { (N=27) }\end{array}$ & $\begin{array}{c}\text { Competition } \\
\text { Projects 2 } \\
\text { (N=10) }\end{array}$ \\
\hline During the course of this project, to what extent did you: & & \\
\hline Explore a contrarian view of accepted (i.e., typical) solutions. & 3.33 & 3.30 \\
\hline Identify an unexpected opportunity for your design. & 3.07 & 2.90 \\
\hline Create extraordinary value for a customer or stakeholder. & 3.22 & 2.40 \\
\hline Integrate information from many sources to gain insight. & 3.63 & 3.80 \\
\hline $\begin{array}{l}\text { Assess and manage risk (i.e., include contingency plans due to } \\
\text { unforeseen design flaws). }\end{array}$ & 3.30 & 3.60 \\
\hline Persist through failure. & 3.81 & 4.00 \\
\hline Apply creative thinking to ambiguous problems. & 3.56 & 3.60 \\
\hline Apply systems thinking to complex problems. & 3.48 & 3.10 \\
\hline Evaluate economic drivers. & 3.19 & 2.40 \\
\hline Examine a customer's or stakeholder's needs. & 3.22 & 3.00 \\
\hline Understand the motivations and perspectives of others. & 3.42 & 3.70 \\
\hline Convey engineering solutions in economic terms. & 3.44 & 2.80 \\
\hline Substantiate claims with data and facts. & 3.67 & 3.60 \\
\hline
\end{tabular}

To get a better view of student responses, histograms were plotted of student responses for the four highest rated responses, as shown in Figure 5. While Introduction to Projects and Competition Projects 2 students had similar distributions for "integrate information from many sources to gain insight," the others do not appear as similar. It makes sense intuitively that students in Competition Projects 2 have completed a much larger project with more opportunities to "persist through failure," resulting in higher ratings. However, this difference was not significant ( $p>0.1)$. It was surprising that responses for "substantiate claims with data and facts" were not higher, as this would include all technical reports and oral presentations. 


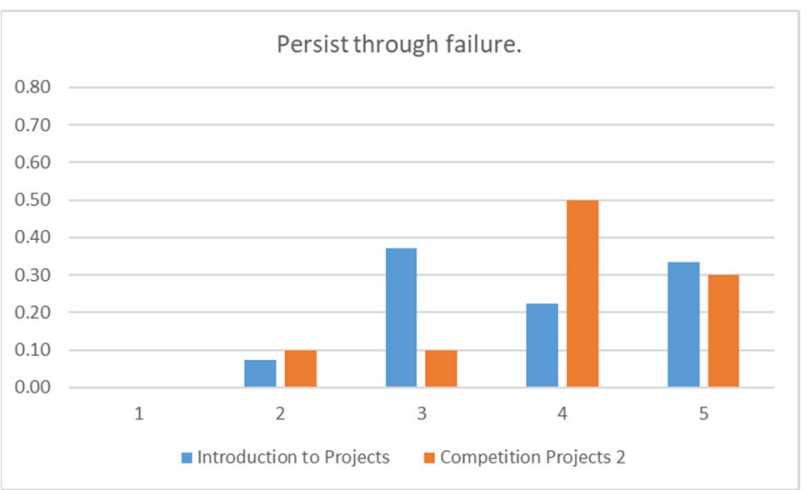

Substantiate claims with data and facts.

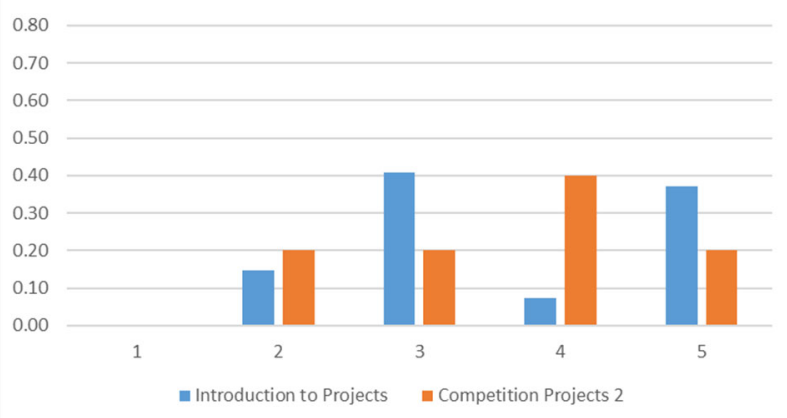

Integrate information from many sources to gain insight.

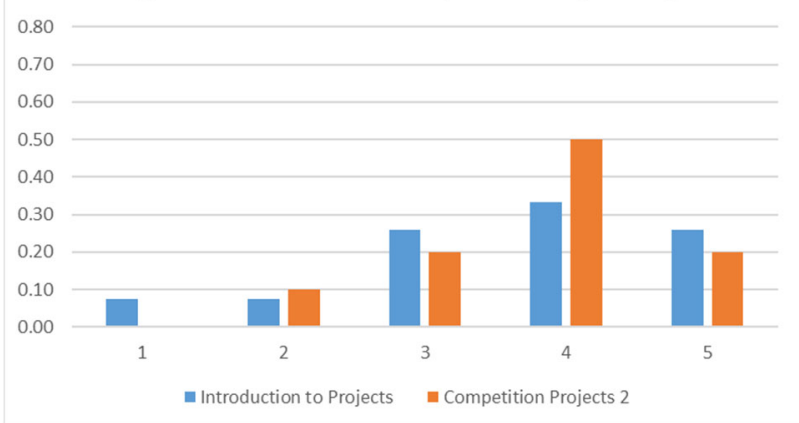

Apply creative thinking to ambiguous problems.

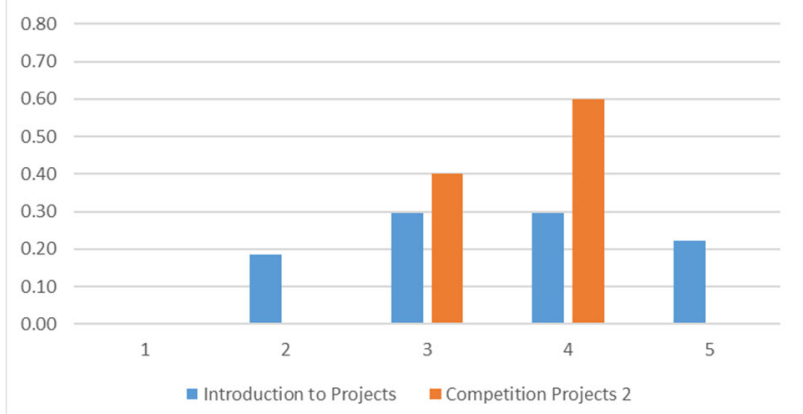

Figure 5. Student self-reported demonstration of example behaviors associated with an entrepreneurial mindset with highest-rated dimensions as a proportion of total response. Using a scale of 1 to 5, 1 indicates "none at all" and 5 indicates "throughout most of the project."

Similarly, histograms were plotted of student responses for the three lowest rated responses, as shown in Figure 6. The difference in responses between Introduction to Projects and Competition Projects 2 students for "create extraordinary value for a customer or stakeholder" was significant $(\mathrm{p}<0.1)$, but the differences for "evaluate economic drivers" and "identify an unexpected opportunity for your design" were not significant. Particularly surprising were the low ratings for "evaluate economic drivers" despite the need for a business plan in several CDS competitions. Anecdotally, the business plan has been handled by only a few students in each team. Responses for "identify an unexpected opportunity for your design" appear normal, perhaps indicating a neutral response because students do not understand an "unexpected opportunity." This should be addressed in future work. 

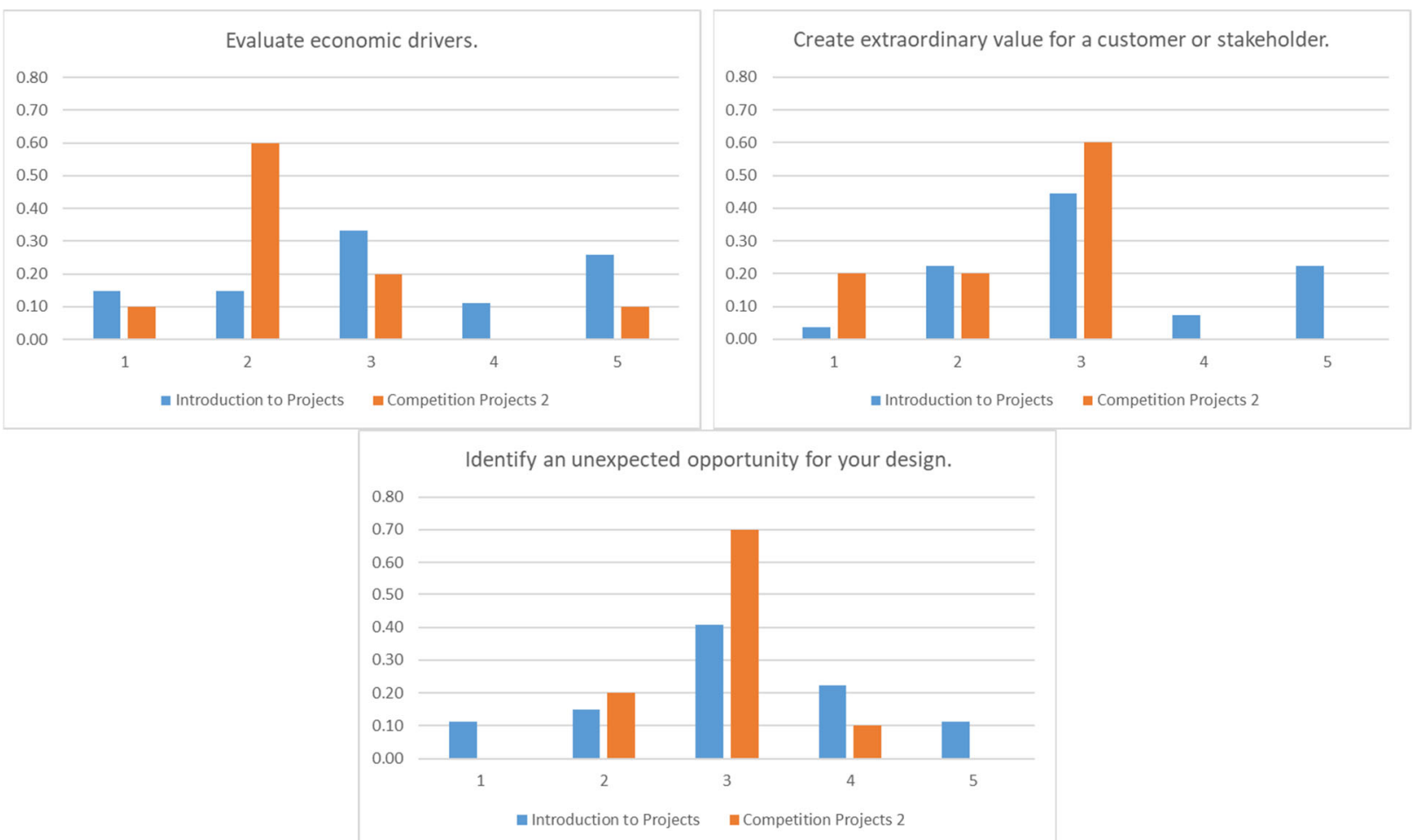

Figure 6. Student self-reported demonstration of example behaviors associated with an entrepreneurial mindset with lowest-rated dimensions as a proportion of total response. Using a scale of 1 to 5, 1 indicates "none at all" and 5 indicates "throughout most of the project."

Table 4 presents students' average ratings of the extent to which they worked with their team. Responses are also presented in a histogram in Figure 7. Unsurprisingly, students report working in teams extensively. This does not, however, address the question of whether or not students are providing leadership or creating an inclusive environment. Peer evaluations are used in all three semesters, but anecdotal evidence suggests that not all students take those evaluations seriously. Future work should include review and revision of the peer evaluation method.

Table 4. Students' average ratings of team work. Using scale of 1 to 5, 1 indicates "almost never" and 5 indicates "almost always."

\begin{tabular}{|l|c|c|}
\hline & $\begin{array}{c}\text { Introduction } \\
\text { to Projects } \\
(\mathrm{N}=27)\end{array}$ & $\begin{array}{c}\text { Competition } \\
\text { Projects 2 } \\
(\mathrm{N}=10)\end{array}$ \\
\hline To what extent did you work with your team & 4.00 & 4.20 \\
\hline
\end{tabular}




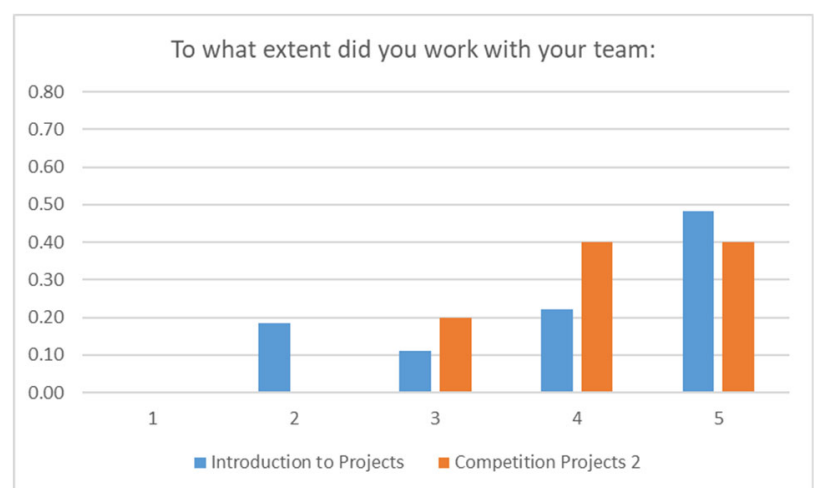

Figure 7. Student self-reported extent of team work as a proportion of total response. Using a scale of 1 to 5, 1 indicates "almost never" and 5 indicates "almost always."

Table 5 presents students' average ratings of improvement in organizational skills. Responses are also presented in histograms in Figure 8. Most students indicated that the projects improved their skills in project organization, time management, and project management. The low ratings from students in Introduction to Projects were from the same three students in each case. From these results, it is clear that the capstone design sequence, either by design or as a function of being a capstone design sequence, contributes to improved organizational skills.

Table 5. Student's average ratings of improvement in organizational skills. Using scale of 1 to 5, 1 indicates "strongly disagree" and 5 indicates "strongly agree."

\begin{tabular}{|l|c|c|}
\hline & $\begin{array}{c}\text { Introduction } \\
\text { to Projects } \\
(\mathrm{N}=27)\end{array}$ & $\begin{array}{c}\text { Competition } \\
\text { Projects 2 } \\
(\mathrm{N}=10)\end{array}$ \\
\hline This project improved my technical skills in: & & \\
\hline Project organization. & 4.00 & 4.30 \\
\hline Time management. & 4.22 & 4.50 \\
\hline Project management. & 4.00 & 4.40 \\
\hline
\end{tabular}




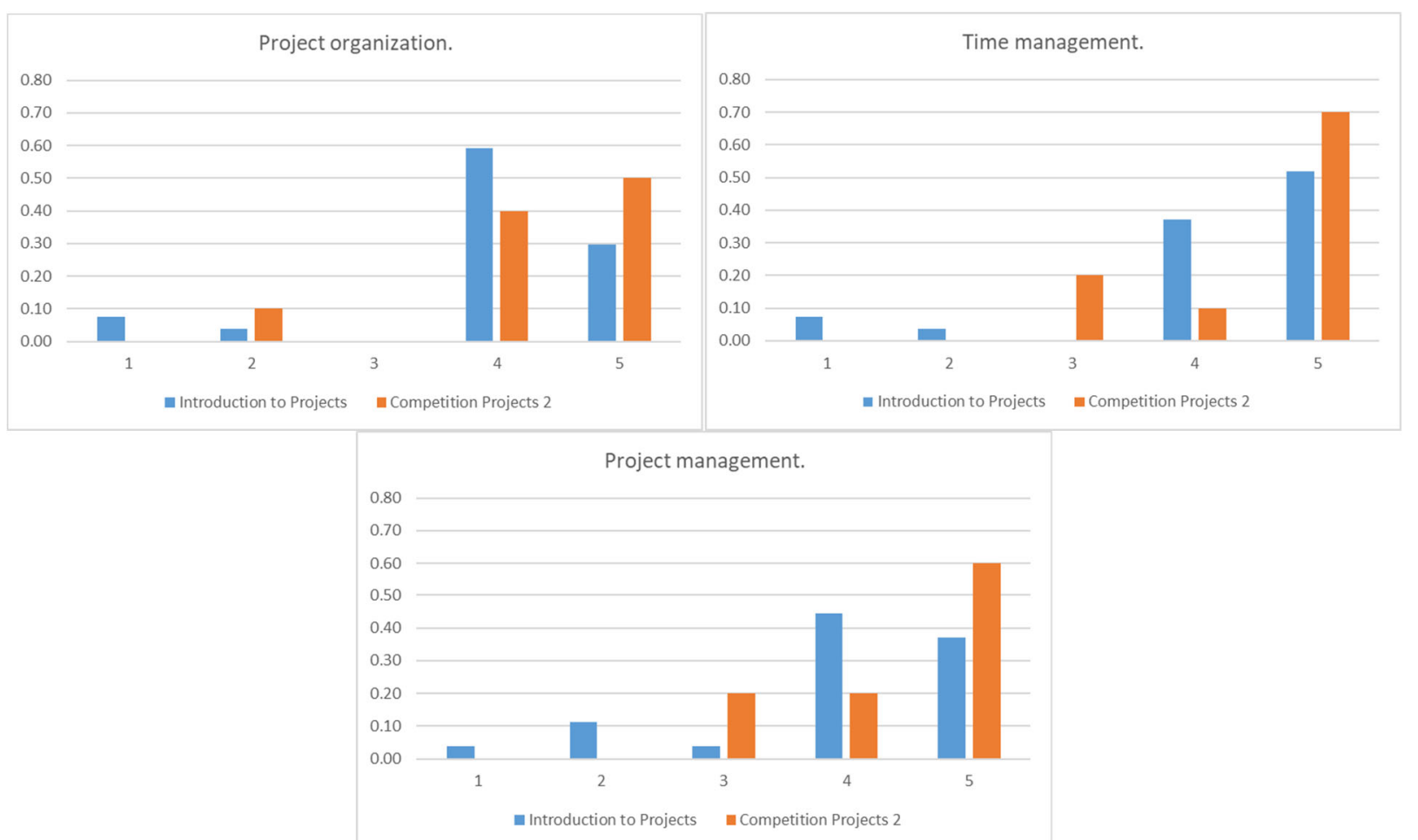

Figure 8. Student self-reported improvement in organizational skills. Using scale of 1 to 5, 1 indicates "strongly disagree" and 5 indicates "strongly agree."

\section{Conclusions}

The Mechanical Engineering faculty at LTU modified the three-semester capstone design sequence. Besides the technical content, the courses were designed to incorporate development of an entrepreneurial mindset and organizational skills into student learning. The outcome was assessed through student surveys in both the Intro to Projects course (the beginning of the sequence) and Competition Projects 2 (the end of the sequence) to evaluate the development of an entrepreneurial mindset after student activities. The results indicated that the students work extensively as a team, and exhibit many example behaviors associated with an entrepreneurial mindset as defined by the KEEN framework and LTU. The four example behaviors that had the highest ratings were "Persist through failure," "Integrate information from many sources to gain insight," "Substantiate claims with data and facts," and "Apply creative thinking to ambiguous problems." It is unclear whether the students' entrepreneurial mindset strengthens during the three-semester sequence, but larger sample sizes and potentially pre- and post-course surveys can be obtained from future offerings. The results do indicate that the students' organizational and management skills do increase from the first to the third semesters. Again, with larger sample sizes, this result can be further investigated. In conclusion, comparing student teams from the original sequence of capstone courses to the teams of the current sequence, the faculty advisors of the CDS teams are noticing better adherence to rules (i.e., understanding the needs of the stakeholders), streamlined design processes allowing for earlier fabrication and testing (an indicator of both better organizational skills and application of systems thinking to complex problems), and a higher value associated with their product (i.e., the vehicle). While this is based on informal assessment (i.e., observation), the faculty advisors have many years of experience 
with CDS team performances, and they are confident in the changes they are detecting. Focus groups with CDS alumni and current students may reinforce these observations of the advisors. Nonetheless, continual improvement is being sought with regards to the entrepreneurial mindset of the students, and improvement to assessment techniques will be sought to ultimately produce better graduating engineers.

\section{Acknowledgments}

The authors thank Dr. Arslan and Dr. Xie for their contributions as project advisors during the course of the work described. The authors also acknowledge support of this work at all levels of administration by Dr. Jawad, Dr. Grace, and Dr. Vaz.

\section{References}

[1] J. Mynderse, S. Arslan and L. Liu, "Using A Funded Capstone Project To Teach Fluid Power," ASME 2014 International Mechanical Engineering Congress and Exposition, 2014.

[2] J. A. Mynderse, A. Sandstrom and Z. Sun, "Dynamic Decoupling of Driveline Dynamics from NVH Driveline Dynamometer: an Industry Sponsored Senior Design Project," SAE 2015 Noise and Vibration Conference and Exhibition, 2015.

[3] J. A. Mynderse, R. W. Fletcher, L. Liu, A. L. Gerhart, S. Arslan and K. E. Yee, "A Three-Semester Mechanical Engineering Capstone Design Sequence Based on an SAE Collegiate Design Series," ASEE Annual Conference \& Exposition, 2016.

[4] B. S. Bloom, Taxonomy of Educational Objectives: The Classification of Educational Goals. Book I: Cognitive Domain, Longman, 1956.

[5] J. A. Mynderse, L. Liu, A. Gerhart, X. Xie, W. Jing and K. Yee, "Assessment of a Three-Semester Mechanical Engineering Capstone Design Sequence Based on the SAE Collegiate Design Series," WCX SAE World Congress Experience, 2019.

[6] K. L. Wood, R. E. Mohan, S. Kaijima, S. Dritsas, D. D. Frey, C. K. White, D. D. Jensen, R. H. Crawford, D. Moreno and K.-L. Pey, "A Symphony of Designiettes: Exploring the Boundaries of Design Thinking in Engineering Education," 2012 ASEE Annual Conference \& Exposition, 2012.

[7] C. A. Cooper, M. L. Anderson, C. Bruce, S. G. Dorman, D. D. Jensen, K. Otto and K. L. Wood, "Designettes in Capstone: Initial Design Experiences to Enhance Students' Implementation of Design Methodology," 2015 ASEE Annual Conference \& Exposition, 2015.

[8] A. L. Gerhart and D. D. Carpenter, "Campus-wide Course Modification Program to Implement Active \& Collaborative Learning and Problem-based Learning to Address the Entrepreneurial Mindset," 2013 ASEE Annual Conference \& Exposition, 2013.

[9] A. L. Gerhart and R. W. Fletcher, "Project-Based Learning and Design Experiences in Introduction to Engineering Courses: Assessing an Incremental Introduction of Engineering Skills," 2011 ASEE Annual Conference \& Exposition, 2011.

[10] A. L. Gerhart, D. D. Carpenter, R. W. Fletcher and E. G. Meyer, "Combining Discipline-specific Introduction to Engineering Courses into a Single Multidiscipline Course to Foster the Entrepreneurial Mindset with Entrepreneurially Minded Learning," 2014 ASEE Annual Conference \& Exposition, 2014.

[11] L. Liu, J. A. Mynderse, A. L. Gerhart and S. Arslan, "Fostering the Entrepreneurial Mindset in the Junior and Senior Mechanical Engineering Curriculum with a Multi-Course Problem-based Learning Experience," 45th IEEE Frontiers in Education Conference, 2015.

[12] E. G. Meyer and M. Nasir, "Fostering the Entrepreneurial Mindset Through the Development of Multidisciplinary Learning Modules Based on the "Quantified Self" Social Movement," 2015 ASEE Annual Conference \& Exposition, 2015.

[13] J. A. Mynderse, J. N. Shelton and A. Gerhart, "Entrepreneurially Minded Learning in a Semester-Long Senior/Graduate Mechatronic Design Project," ASME 2017 Dynamic Systems and Control Conference, 2017. 
[14] K. A. Smith, S. D. Sheppard, D. W. Johnson and R. T. Johnson, "Pedagogies of Engagement: ClassroomBased Practices," Journal of Engineering Education, vol. 94, no. 1, pp. 87-101, 2005.

[15] K. A. Smith, "Cooperative learning: Lessons and insights from thirty years of championing a research-based innovative practice," Frontiers in Education Conference (FIE), 2011.

[16] M. Prince, "Does Active Learning Work? A Review of the Research," Journal of Engineering Education, vol. 93, no. 3, pp. 223-231, 2004.

[17] A. Yadav, D. Subedi, M. A. Lundeberg and C. F. Bunting, "Problem-based Learning: Influence on Students' Learning in an Electrical Engineering Course," Journal of Engineering Education, vol. 100, no. 2, pp. 253280, 2011.

[18] C. Hsieh and L. Knight, "Problem-Based Learning for Engineering Students: An Evidence-Based Comparative Study," The Journal of Academic Librarianship, vol. 34, no. 1, pp. 25-30, 2008.

[19] M. J. Prince and R. M. Felder, "Inductive Teaching and Learning Methods: Definitions, Comparisons, and Research Bases," Journal of Engineering Education, vol. 95, no. 2, pp. 123-138, 2006.

[20] D. W. Johnson, R. T. Johnson and K. A. Smith, "Cooperative Learning Returns To College What Evidence Is There That It Works?," Change: The Magazine of Higher Learning, vol. 30, no. 4, pp. 26-35, 1998.

[21] A. L. Gerhart and D. E. Melton, "Entrepreneurially Minded Learning: Incorporating Stakeholders, Discovery, Opportunity Identification, and Value Creation into Problem-based Learning Modules with Examples and Assessment Specific to Fluid Mechanics," Journal of Engineering Entrepreneurship, vol. 8, no. 1, pp. 44-62, 2017.

[22] Kern Entrepreneurial Engineering Network (KEEN), "KEEN Framework," [Online]. Available: https://keenwarehouseprod.blob.core.windows.net/keen-downloads/KEEN_Framework_spread.pdf.

[23] Kern Entrepreneurial Engineering Network (KEEN), "Entrepreneurial Mindset 101," [Online]. Available: https://engineeringunleashed.com/EM-Series.aspx?seriesId=101.

[24] S. Condoor and M. McQuilling, "Incorporating An Entrepreneurial Mindset In Freshman Engineering Students," 2009 ASEE Annual Conference \& Exposition, 2009.

[25] W. M. Jordan, C. C. Fry and K. W. V. Treuren, "Promoting the Entrepreneurial Mindset through Faculty Development," 2016 ASEE Annual Conference \& Exposition, 2016.

[26] M.-I. Carnasciali, R. S. Harichandran, N. O. Erdil, J. Nocito-Gobel and C. Q. Li, "Integrated e-Learning Modules for Developing an Entrepreneurial Mindset: Direct Assessment of Student Learning," 2018 ASEE Annual Conference \& Exposition, 2018.

[27] N. Duval-Couetil, J. Wheadon, E. Kisenwether and J. Tranquillo, "Entrepreneurship and ABET accreditation: How and where does it fit?," IEEE Frontiers in Education Conference (FIE), 2013.

[28] I. Hilliger, C. M. Mendoza, M. Pérez-Sanagustín and M. D. 1. Vega, "Does the Revision of ABET Student Outcomes Include the Competencies Required to Succeed in Start-Ups and Entrepreneurial Companies?," 2017 ASEE Annual Conference \& Exposition, 2017. 